\title{
PALAEOLITHIC ZOOARCHAEOLOGY IN MYANMAR: A REVIEW AND FUTURE PROSPECTS
}

\author{
Tin Htut Aung ${ }^{1}$, Ben Marwick ${ }^{2} \&$ Cyler Conrad ${ }^{3}$
}

\begin{abstract}
${ }^{1}$ Department of Archaeology, University of Yangon, Myanmar, ${ }^{2}$ Center for Archaeological Science, University of Wollongong, Australia \& Department of Anthropology, University of Washington, USA, ${ }^{3}$ Department of Anthropology, University of New Mexico, Albuquerque, USA
\end{abstract}

\begin{abstract}
The Anyathian culture, one of the prominent stone artefact traditions in Mainland Southeast Asia spanning the Pleistocene and Holocene, has been frequently described at archaeological sites in the central belt of Myanmar. Human exploitative patterns of plant and animal resources relating to the Anyathian are obscure due to the paucity of systematic stratigraphic excavations in Myanmar. However, recent research in the States of Shan and Kayin has shown that Myanmar has the potential to contribute to a better understanding of human subsistence economies at hunter-gatherer sites throughout the Pleistocene and Holocene. This study reviews faunal evidence recovered in association with stone artefacts at huntergatherer sites throughout Myanmar and illustrates the significance that further, more intensive research and better chronometric dating has for developing our understanding of foraging strategies in the Late Pleistocene and Holocene in Myanmar.
\end{abstract}

Keywords: Anyathian Culture, archaeozoology, subsistence, Palaeolithic, Myanmar

\section{INTRODUCTION}

A number of sites attributed to the Palaeolithic period have been found in the central belt, or Ayeyarwady River catchment, of Myanmar since 1870 (Figure 1). Some of the earliest systematic surveys and reconnaissance work on open sites along the course of the Ayeyarwady River was undertaken by Movius and de Terra (1943: 346) who identified exposed cultural remains that they attributed, through association between geological sequences and cultural remains, to the Pleistocene period. During these investigations they collected more than 650 stone artaefacts (Movius and de Terra 1943: 387- 391). Subsequent exploration of the same sites surveyed by Movius and de Terra by members of the Department of Archaeology, Ministry of Culture, Myanmar, between 2008-2009 produced another 800 Palaeolithic stone implements (Win Kyaing 2008: 1-7). Movius used the term 'Anyanthian' as a general label for the stone artefacts he collected, which were typically large pieces of fossilized wood, heavily

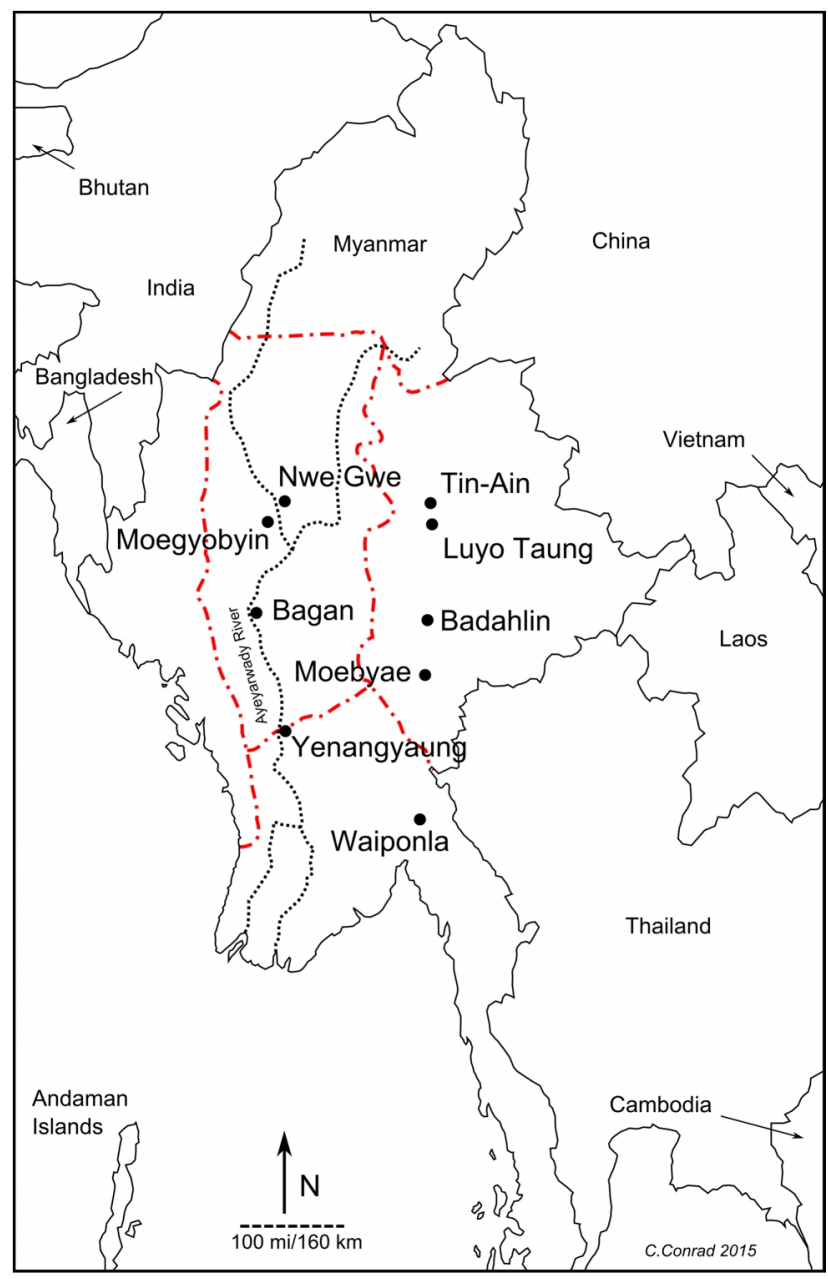

Figure 1: Locations of sites mentioned in the text. The dash-dotdash line shows the boundaries of the five rainfall regions of Myanmar.

water-rolled, with a small number of fracture surfaces. No absolute dating methods were available to Movius, and he estimated a Middle to Late Pleistocene age for the Anyathian. Movius' interpretations of the collected items have been challenged in recent years, with few archaeologists accepting the chronology of the artefacts and terraces that he proposed, and there is doubt that many of the pieces he collected have been intentionally flaked (Dennell 2014; 
Rendell et al. 1989). However, until more archaeological research is completed in central Myanmar to empirically assess Movius' claims and provide an alternative framework, the Anyanthian is likely to remain a convenient label, especially among archaeologists within Myanmar for assemblages that are obviously not Hoabinhian or Neolithic.

Other archaeological investigations in more recent years have helped to identify several more prehistoric sites throughout Myanmar. These include Tin-Ain Cave, Luyo Taung, Badahlin Cave (formerly known as Padahlin Cave), Nwe Gwe Hill, Moegyobyin open air site and Waiponla Cave. All of these investigations have contributed new information and perspectives on Palaeolithic archaeology from a wide region across Myanmar. Most of these research projects have focused on evidence obtained from lithic assemblages and how the distribution of these stone tools potentially inform on Palaeolithic settlement patterns. The faunal evidence from these sites is less understood and there is substantial variation in the level of detail reported on recovery methods and assemblage composition. In most cases there are no details on sieve sizes, excavation unit volumes or other basic information about field methods. Crucial information about the context of the material that has been radiocarbon dated is also not available. Despite these shortfalls, we believe that the brief survey of zooarchaeological evidence from past excavations in Myanmar presented here will help to facilitate comparisons with the wider region, and stimulate further research in Myanmar. We discuss how, in the future, and when supported by more precise chronometric dating, archaeology in Myanmar has the potential to contribute to the developing discourse on hunter-gatherer subsistence strategies from the Late Pleistocene and Holocene across Mainland Southeast Asia.

\section{RECOVERY AND ANALYSIS OF ZOOARCHAEOLOGICAL REMAINS FROM CAVES AND ROCKSHELTERS IN MYANMAR}

\section{Palaeolithic Chronologies, Climates and Landscapes in Myanmar:}

Most contemporary archaeological studies in Myanmar focus on historical periods and monumental structures, and as a result there has been little scientific research effort devoted towards investigating Palaeolithic sites and constructing robust chronologies. Thus, the prevailing chronological framework is based upon stone artifact typologies and the problematic assumption that artefacts are likely to be of the same age as the stable land surfaces they were recovered from. For example, Movius suggested that the Ayeyarwady Valley terraces were likely of Pleistocene age due to their position within the regional geological stratigraphy, and therefore the stone artefacts recovered from the exposed surfaces of these terraces must also be of Pleistocene age. The obvious problem with this claim is that the artefacts could have been deposited on the terrace surface at any time after exposure and stabilization (Dennell 2014). Moore (2007: 47) has recently argued in support of a Pleistocene age for the
Ayeyarwady Valley in the central belt of Myanmar by suggesting they were occupied sometime between 750,000 and $25,000 \mathrm{BP}$, but there are no absolute dates to support this claim, and Dennell (2014) strongly challenges these ages. Limited financial resources for local archaeological projects make it difficult to afford absolute dating analyses, and thus geological strata such as river terraces and stone artifact typologies similar to those utilized in the Ayeyarwady Valley remain the main criteria used for the relative dating of Pleistocene and early Holocene cave, rockshelter and open air sites across Myanmar. These have wide error margins and their chronological resolution is extremely limited.

Ecological and climatological data for Myanmar is also scant. The modern climate is impacted by the Indian/Asian monsoon as well as convective rainfall from the Bay of Bengal. The annual climate is strongly seasonal, linked to monsoon cycles and mountainous rain-shadow effects (Kondoh et al. 2004). Using 33 years (1947-1979) of station level monthly data, Sen Roy and Kaur (2000) describe five homogenous precipitation regions, namely, north Myanmar, west Myanmar, central Myanmar, east Myanmar and south Myanmar. The sites discussed here fall into the central and east regions, which have the lowest annual rainfall $(68 \mathrm{~cm}$ and $89 \mathrm{~cm}$ per year) of all five regions. The highest is the west region, with $301 \mathrm{~cm}$ per year. Tree ring data from central Myanmar (also known as the dry region) indicates that over the last 300 years, local climates are significantly correlated with larger-scale climate indices, including core Indian rainfall and the El Niño-Southern Oscillation (D'Arrigo et al. 2011). Direct evidence of Holocene and Pleistocene climates is not yet available for Myanmar.

The archaeological sites discussed here mostly occur on the Shan Upland and Central Belt landforms (Huke 1965). The Shan Uplands is a deeply dissected plateau that is mostly composed of steeply rolling hills. The surface geology is dominated by limestone, sandstone, metamorphic rocks and granites. This region is sharply defined from the Central Belt by a well-defined north-south fault scarp that produces orographic rainfall and cool air at one of the most distinct and stable climate boundaries in the country. The Central Belt, in contrast to the Shan Uplands, is characterized by surface deposits of alluvial sediments, with broad valleys and isolated ranges of low hills. In some areas the sediments have consolidated into sandstones and shales.

\section{Recovery of Zooarchaeological Remains}

\section{Yenangyaung}

Fritz Noetling (1897) described assemblages of stone artefacts and animal bones from Yenangyaung. In his analysis Noetling described the broken femur of a hippopotamus, which he considered to be in association with stone artefacts; though, some scholars considered this association nothing more than natural activity (Brown 1931: 31-37; Movius 1935: 1-39). Still, the discovery stimulated further research into ancient faunal communities and stone artifact assemblages in the region. Morris 
(1935: 1-4) attempted unsuccessfully to assign lithic implements and recovered faunal and floral assemblages to cultural sequences within observed geological successions. Unfortunately, the associations between artifact types and various taxa were too weak for robust interpretation.

\section{Tin-Ain rockshelter}

As well as survey and excavation in the Ayeyarwady Valley, the American Expedition of 1937-38 led by Movius also investigated sites in Shan State. Here, they first documented the remains of animals potentially exploited by Palaeolithic groups. This included excavations in TinAin rockshelter where Movius and colleagues recovered animal bones and shells in association with scattered ash and charcoal (Bequaert 1943: 431). In spite of the paucity of artefacts, Movius argued that the burnt and broken bones reflected human activity, rather than natural processes of deposition (Movis and de Terra 1943: 390). Another member of the American Expedition, the palaeozoologist J. Bequaert (1943: 395, 431) also noted that the animals represented were wild species and not domesticates. In association with freshwater shells, he suggested that they were probably transported to, and consumed within the cave by prehistoric hunter-gatherers.

Though the absence of a coherent stratigraphy and lack of correspondence makes it difficult to link bones with artefacts and estimate the age of the archaeological remains (cf. Dennell 2014), Gorman (1971a) considered the mammalian bones from Tin-Ain to have resulted from the activities of ancient foragers. Four taxa have been formally identified Eld's deer (Rucervus eldii), Indochinese hog deer (Axis porcinus), Sambar deer (Rusa unicolor) and an unidentified species of rhinoceros (Rhinocerotidae), along with two species of fresh water snail, Taia intermedia and Brotia persculpta (Movius and de Terra 1943: 390). From these identifications, Gorman (1971a) argued that the taxa recovered were similar to those identified in other caves throughout Southeast Asia and were associated with radiocarbon dates of Pleistocene and Early Holocene age. More recently, a test pit was excavated at Tin-Ain by a team of archaeologists from the Department of Archaeology under the Ministry of Culture, Myanmar, to define the possible cultural layers dug by the 1937-38 American expedition. Disturbance through the construction of modern religious monuments inside the cave has destroyed all traces of the ancient cultural deposits (Kyaw Khaing 2012: 11- 13).

\section{Luyo Taung}

Luyo Taung (formerly known as Ayū Taung) was first excavated by the American Expedition team in 1937-38 and then re-excavated by Thein in the 1990s. The site has produced small assemblages of animal bone associated with Palaeolithic tools. At least two species of cattle and Eld's deer are represented. The cattle remains are highly fragmented negating specific identification and determination of wild (Bibos sondaicus) versus domestic (Bos Taurus; Thein 2011) forms. Thein (2011: 183-184) also noted the absence of carnivore bones in the assemblage and that it was more likely humans had been responsible for the bone accumulations than carnivores or scavengers. Following the same reasoning he had presented for TinAin, the close affinities between the faunal communities identified at Luyo Taung and those recorded elsewhere in SEA probably mean that the site dates to the Pleistocene/Holocene transition (Gorman 1971a: 307).

\section{Badahlin Cave}

In 1969 a Department of Archaeology team led by Aung Thaw $(1969,1971)$ recovered a substantial animal bone assemblage in association with 1600 stone artefacts, a few pieces of charcoal, some fragments of pottery and red ochre in Badahlin Cave, Shan State. Prehistoric rock art was also identified on the cave walls (Aung Thaw 1971: 127-129, Tacon et al. 2004; Than Tun 2004). Different scholars have associated the cultural remains from Badahlin to the upper Palaeolithic (Than Tun 2004: 41-42), Mesolithic (Myint Aung 2000: 1-16) and to the Neolithic (Aung Thaw 1971: 123-133). Of the seven radiocarbon dates published by Aung Thaw (1971: 133) the oldest is $13,400 \pm 200 \mathrm{BP}(\mathrm{R} 2547 / 5 \mathrm{~B})$ suggesting that at least some of the human occupation probably dates to the Pleistocene-Holocene transition (the youngest age is $1750 \pm 81$ BP R2547/1). No information is available about the specific recovery contexts of these dates. Little systematic zooarchaeological analysis has yet been undertaken on the bone from Badahlin Cave, but Mya Muang (1971) has suggested that that the majority of vertebrates were herbivorous artiodactyl species along with some aquatic species (shellfish). All appear to have been hunted and collected by hunter-gatherers inhabiting the cave.

\section{Nwe Gwe Hill and Moegyobyin}

In 1981, Ba Maw (1995: 76) also discovered a fossilized mandible fragment that he identified as Homo erectus in association with wild boar (Sus sp.) and dog (Canis sp.) remains at Nwe Gwe Hill in Chaung U Township. According to the taxonomic list, at least 'six classes' of faunal remains were discovered in association with flaked stone artefacts (Ba Maw 1995: 76). Ba Maw (1995: 74) claimed a date of 200,000 years for these finds, but there has been no absolute dating obtained for the site and no verification of the authenticity of the hominin identification. The possibility of additional Homo erectus remains highlights the research potential of this location, but no additional work has been carried out to date. Ba Maw also collected stone artefacts and animal bones from nearby Moegyobyin. These were studied by Nwe Nwe Moe (2014), who attempted to interpret patterns of human activity and subsistence strategies using taxonomic identification and community composition. The analysis was hindered by the highly fragmented nature of the bone assemblages, but the dominant taxa appear to have been Bovidae and Suidae (Nwe Nwe Moe 2014: 54-55). A single specimen exhibited butchery marks, suggesting that people were almost certainly responsible for the accumulation of at least some of the remains. An outstanding 
problem once again was the difficulty in dating the animal bone assemblages. They were all collected as surface finds and it is possible that they represent a palimpsest that developed over a considerable time period. Therefore, the provenance and association of the faunal remains and lithic artefacts at Nwe Gwe and Moegyobyin sites requires further verification by systematic stratigraphic excavations and chronometric dating.

\section{Moebyae Cave}

Moebyae Cave has produced a zooarchaeological assemblage in association with Neolithic material culture including polished and ground stone adzes, estimated to be between 6000-4000 years old (Thein 2011: 130; Than Tun Aung 2002). Thein (2011: 184) argued that the foragers frequenting Moebyae Cave hunted a variety of herbivorous and carnivorous species, including Gaur (Bibos gaurus), cattle (Bibos sondaicus), Eld's deer (Rucervus eldi), Sambar deer (Rusa unicolor), cats (Felis sp.), gibbons (Hylobates), porcupine (Hystrix), and wild boar (Sus scrofa). Human remains included the molar of a child and two teeth of an adult. The structure of the captured fauna shows marked differences from that identified at Luyo Taung, and it is possible that this indicates the application of disparate subsistence strategies at the two caves and raises questions about what caused the differential representation of carnivores at Moebyae Cave.

\section{Waiponla}

The most extensive zooarchaeological study in Myanmar was conducted on the vertebrate remains from Waiponla, a limestone cave located in Kayin State, excavated by Tin Thein and colleagues in 2000 (Tin Thein et al. 2001; 2011: 99). During their excavation, Tin Thein unearthed a layer containing assemblages of lithic artefacts and ecofacts, which he described as a "cal-tufa bed" (Tin Thein et al. 2001: 1). Tin Thein suggests that the faunal remains were deposited by prehistoric occupants who discarding them after they were processed and consumed as food (Tin Thein 2011: 100-101). The date of prehistoric human occupation of Waiponla Cave is claimed by Tin Thein et al. (2001: 5), to be around 12,000 to 6,000 years ago based upon the similarity of stone artefact typology with Badahlin Cave, which has radiocarbon dates extending back to the terminal Pleistocene (see above, Myint Aung 2000: 9). Identified species include barking deer (Muntiacus muntjak), Eld's deer, Sambar deer, Gaur, wild boar, Hog deer, fish (Osteichthyes) and turtle (Chelonii/Testudines; Tin Thein et al. 2001: 3-4), but no quantitative information on the composition of the vertebrate community is available. Conrad (2015) has suggested that the taxa representation potentially reflects similar foraging patterns to those observed at Palaeolithic sites elsewhere in Mainland Southeast Asia, and that sites in Myanmar correspond to regional trends in hunter-gatherer foraging strategies. Due to the quality of the zooarchaeological record from Waiponla the site is considered extremely significant and could produce substantial new information on Southeast Asian foragers, similar to Pleis-
tocene-Holocene cave sites like Ma U'Oi Cave, northern Vietnam and Tham Lod Rockshelter, Thailand (Bacon et al. 2004: 309-312; Shoocondgej 2006: 22-37).

\section{Zooarchaeological Research and Palaeolithic Archaeolo-} gy in Myanmar: Future Direction

Though currently sparse, the recovery of animal bones from open sites and karst limestone caves and rockshelters provide an intriguing glimpse at what future zooarchaeological research in Myanmar possesses (Table 1). The Anyathian sites in the central belt of the Ayeyarwady Basin have produced some tantalizing evidence for the presence of vertebrate communities that could date to the Middle Pleistocene (or earlier)-onwards. This also includes provocative claims for the presence of Homo erectus (Ba Maw 1995). These open-air sites are very exposed to weathering and preservation is generally poor, but they may present an opportunity to investigate hominin foraging strategies across a broad chronological timeframe.

So far, the best-preserved animal bone assemblages identified in Myanmar have been recovered from karst limestone cave sites such as Badahlin and Waiponla. Though limited in scope, zooarchaeological analysis has identified a diversity of vertebrates and invertebrates including barking deer, Eld's deer, Sambar deer, Gaur, wild pig, Hog deer, rhinoceros, wild cattle or banting, fish, turtle, and mollusks. Myanmar is inhabited by a broad diversity of vertebrate taxa (see Lekagul and McNeely 1977; Francis 2008) and there is no doubt that future research will increase our understanding of late Pleistocene and early Holocene foragers throughout this region (see Barton et al. 2013). The geographic distribution of Palaeolithic sites in Myanmar, within karst limestone and along riverine systems, makes them comparable to hunter-gatherer occupation across Mainland Southeast Asia (see Gorman 1971a, b). It is intriguing to note that the majority of taxa identified so far, though very provisional, consist primarily of deer taxa (Cervidae). This has strong similarities with observations of Palaeolithic hunting strategies in Thailand where Conrad (2015) has argued that these grazers, along with Suidae and turtles were some of the principal prey types exploited during the late Pleistocene in Mainland Southeast Asia.

However, further research is required both in terms of archaeological excavation and zooarchaeology. When, during future excavations animal assemblages are recovered from discrete stratigraphic units it will be possible to determine spatial and temporal variability in the vertebrate and invertebrate community composition and structure related to, for example, changes in human foraging strategy and local and regional palaeoenvironments. Establishing the relationships between technological developments and animal exploitation will enhance our understanding of foraging practices. For example, Rabett and Piper (2012) linked the development of projectile technology at the Niah Caves with an observed increase in the hunting of arboreal taxa. They argued that not only were monkeys targeted as a food resource but also as a raw material source for the production of bone implements. 


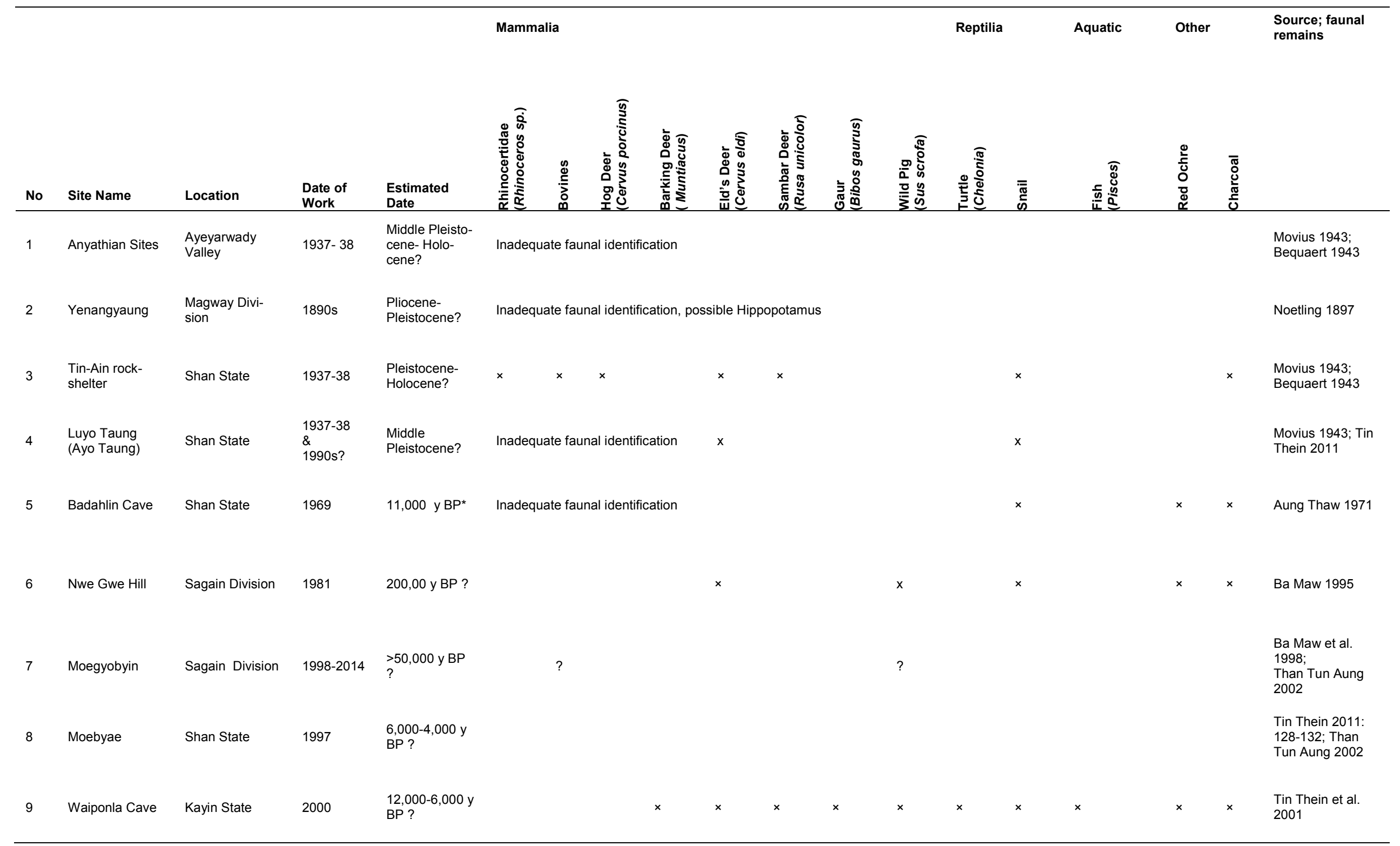

Table 1. Summary of finds for sites mentioned in the text. *=Radiocarbon date, $x=$ Presence of specific fauna, ?=possible presence of taxa. 
The analysis of body part representation and butchery techniques will aid in identifying aspects of human behaviour such as artifact and ornament procurement and skinning. These advancements in archaeological and zooarchaeological research need to coincide with extensive chronometric dating programs so that stratigraphic sequences in both the Ayeyarwady Basin and karst limestone caves and rockshelters can be anchored to solid chronologies.

Myanmar is situated at the crossroads between India to the west and Southeast Asia to the east. With developments in archaeology and the construction of chronological frameworks it has the potential to provide significant new data on hominin migration during the Middle Pleistocene, human adaptation and technical innovation during the late Pleistocene and early Holocene and the emergence of agriculture and exchange in the later Holocene.

\section{REFERENCES}

Aung Thaw, U. 1969. Exploring Padah-Lin Caves. Spectrum 2(1): $162-166$

Aung Thaw, U. 1971. The 'Neolithic' Culture of the Padah-Lin Caves. Asian Perspectives 14: 127-129.

Ba Maw, U, et al. 1998. The First Discovery in the Evolution of Anyathian Cultures from a Single Site in Myanmar. Myanmar Historical Research Journal 2:97-105.

Ba Maw, 1995. The first discovery of Early Man's fossilized maxillary bone fragment in Myanmar. The East Asian Tertiary Quaternary Newsletter 16: 72-79.

Bacon, Annie-Marie et al. 2004. The Pleistocene Ma U'Oi cave, Northern Vietnam: palaeontology, sedimentology and palaeoenvironments. Geobios 37: 309- 312.

Barton, H., Barker, G., Gilbertson, D., Hunt, C., Kealhofer, L., Lewis, H., Paz, V., Piper, P.J., Rabett, R.J., Reynolds, T. \& Szabó, K. 2013. Later Pleistocene foragers c. 35,00011,500 years ago in G. Barker (ed.), 2013: Rainforest Foraging and Farming in Island Southeast Asia: The Archaeology and Environmental History of the Niah Caves, Sarawak, Niah Cave Project Monographs. Cambridge: McDonald Institute Monograph Series pp. 173-216.

Bequaert, J. 1943. Fresh-water shells from cave deposits in southern Shan States, Burma. In Movius, H. L and de Terra, H, (eds). Research on Early Man in Burma, Transactions of the American Philosophical Society, Philadelphia, pp. 432-439.

Brown, J. C, 1931. Relics of the Stone Age in Burma. Journal of Burma Research Society XXI(II): 34- 37.

Conrad, C. 2015. Archaeozoology in Mainland Southeast Asia: Changing methodology and Pleistocene and Holocene forager subsistence patterns in Thailand and Peninsular Malaysia. Open Quaternary 1(7):1-23.

D'Arrigo, R., J. Palmer, C. C. Ummenhofer, N. N. Kyaw, and P. Krusic. 2011. Three centuries of Myanmar monsoon climate variability inferred from teak tree rings, Geophys. Res. Lett. 38: L24705

Dennell, R., 2014. Hallam Movius, Helmut de Terra and the Line that Never Was: Burma, 1938, in: Boyle, K., Rabett, R., Hunt, C. (Eds.), Living in the Landscape: Essays in Honour of Graeme Barker, pp. 11-34.
Francis, C. 2008. A Field Guide to the Mammals of Thailand and South-East Asia. Bangkok: Asia Books.

Gorman, C.F. 1971a. The Hoabinhian and After: Subsistence Patterns in Southeast Asia during the Late Pleistocene and Early Recent Periods. World Archaeology 2(3): 300-320.

Gorman, C.F. 1971b. Prehistoric Research in Northern Thailand: A Cultural-Chronographic Sequence from the Late Pleistocene through to the Early Recent Period. Unpublished thesis $(\mathrm{PhD})$, University of Hawaii.

Huke RE. 1965. Rainfall in Burma. Dartmouth: Geographical Publications.

Kyaw Khaing. 2012. Report on the Discoveries of Stone Age Cultural Evidences by Field Exploration, Department of Archaeology, Unpublished, Ministry of Culture.

Kondoh, A., A. Harto, R. Eleonora, and T. Kojiri. 2004. Hydrological regions in monsoon Asia. Hydrol. Processes 18: 3147-3158,

Lekagul, B. and McNeely, J. 1977. The Mammals of Thailand. Bangkok: Association for the Conservation of Wildlife.

Moore, Elizabeth H. 2007. Early landscapes of Myanmar. Bangkok: River Books.

Morris, T. O, 1935. The prehistoric stone implements of Burma, Journal of the Burma Research Society 25(1): 1-39.

Movius, H. L and de Terra, H, 1943. Research on Early Man in Burma. Philadelphia: Transactions of the American Philosophical Society.

Mya Muang. 1971. Badahlin Cave in Zoological Perspective, Tekkatho Pyinnyar Padethar Sarsaung 6(1): 371- 377. (In Burmese)

Myint Aung. 2000. A Review of Padahlin Culture, Myanmar Historical Research Journal, Yangon 6: 1- 16

Noetling, F. 1897. On the discovery of chipped flint flakes in the Pliocene of Burma. Natural Science 10: 233-241.

Nwe Nwe Moe. $2014 . \quad$ Material Remains of Moegyobyin in Salingyi Township, Sagaing Region, PhD thesis, Department of Archaeology, Univesity of Yangon, Unpublished, Yangon.

Rabett, R.J. and Piper, P.J. 2012. The emergence of bone technologies at the end of the Pleistocene in Island and Mainland Southeast Asia and their regional implications. Cambridge Archaeological Journal 22(1): 37-56.

Rendell, H.R., Dennell, R.W., Halim, M. 1989. Pleistocene and Palaeolithic Investigations in the Soan Valley, Northern Pakistan. British Archaeological Reports International Series 544, Oxford: Archaeopress.

Sen Roy N, Kaur S. 2000. Climatology of monsoon rains of Myanmar (Burma). International Journal of Climatology 20: 913-928.

Shoocongdej, R. 2006. Late Pleistocene Activities at Tham Lod Rockshelter in Highland Pang Mapha, Mae Hong Son Province, Northwestern Thailand. In Bacus, E, Glover, I and Pigott, V (eds.) Uncovering Southeast Asia's Past: Selected Papers from the $10^{\text {th }}$ International Conference of the European Association of Southeast Asian Archaeologists. 22-37.

Tacon, Paul S. C. et al. 2004. Myanmar Prehistory: rare rockmarkings revealed. Archaeology in Oceania 39: 138-139.

Than Tun. 2004. Myanmar History Told in Picture. Yangon: Monyawe Publishing House Press. (In Burmese) 
Than Tun Aung. 2002. A Study on the Stone Artefacts from Moegyobyin and Monywa Region, National Centre for Human Resource Development, Ministry of Education, Yangon. (In Burmese)

Thein, Tin. 2011. Myanmar Stone Age Culture. Yangon: Sapae Beikhman Press. (In Burmese)

Thein, Tin et al., 2001. Evidence of Stone Age Dwellers in Waiponla Cave. Myanmar Historical Research Journal 8: 1-6.

Win Kyaing. 2008. Report on field exploration and the discovery of Prehistoric Stone Age Cultural remains, Unpublished, Ministry of Culture, Mandalay. 